\title{
Trace Determination of Tamoxifen in Biological Fluids Using Hollow Fiber Liquid-Phase Microextraction Followed by High-Performance Liquid Chromatography-Ultraviolet Detection
}

\author{
Amir Kashtiaray ${ }^{1}$, Hadi Farahani ${ }^{2}$, Sharareh Farhadi ${ }^{1}$, Bertrand Rochat ${ }^{3}$, Hamid Reza Sobhi ${ }^{1,3^{*}}$ \\ ${ }^{1}$ Department of Chemistry, Tehran Payamenoor University, Tehran, Iran \\ ${ }^{2}$ Industrial and Environmental Protection Division, Research Institute of Petroleum Industry (RIPI), Tehran, Iran \\ ${ }^{3}$ Quantitative Mass Spectrometry Facility, Centre Hospitalier Universitaire Vaudois, Lausanne, Switzerland \\ E-mail:hrsobhi@gmail.com \\ Received February 27, 2011; revised May 1, 2011; accepted June 17, 2011
}

\begin{abstract}
The applicability of hollow fiber liquid-phase microextraction (HF-LPME) combined with high-performance liquid chromatography-ultraviolet detection (HPLC-UV) was evaluated for the extraction and determination of tamoxifen (TAM) in biological fluids including human urine and plasma. The drug was extracted from a $15 \mathrm{~mL}$ aqueous sample (source phase; SP) into an organic phase impregnated in the pores of the hollow fiber (membrane phase; MP) followed by the back-extraction into a second aqueous solution (receiving phase; RP) located in the lumen of the hollow fiber. The effects of several factors such as the nature of organic solvent, compositions of SP and RP solutions, extraction time, ionic strength and stirring rate on the extraction efficiency were examined and optimized. An enrichment factor of 360 along with substantial sample clean up was obtained under the optimized conditions. The calibration curve showed linearity in the range of 1 $500 \mathrm{ng} \cdot \mathrm{mL}^{-1}$ and the limit of detection was found to be $0.5 \mathrm{ng} \cdot \mathrm{mL}^{-1}$ in aqueous medium. A reasonable relative recovery $(\geq 89 \%)$ and satisfactory intra-assay $(3.7 \%-4.2 \%, n=3)$ and inter-assay $(7.5 \%-7.8 \%, n=3)$ precision illustrated good performance of the analytical procedure in spiked human urine and plasma samples.
\end{abstract}

Keywords: High-Performance Liquid Chromatography-Ultraviolet Detection, Hollow Fiber Liquid-Phase Microextraction, Human Urine and Plasma Samples, Tamoxifen

\section{Introduction}

Sample preparation has a direct impact on accuracy, precision, limits of detection and is a determining step of the analytical process, especially when traces have to be determined [1-6].

The invention of solid phase microextraction (SPME) by Pawliszyn and co-workers [7], basically initiated the interest for microextraction techniques in analytical chemistry. SPME satisfies most of the requirements of a good sample preparation technique, including simplicity of use, automation, and low consumption of materials [8]. Thus, it has been applied to determine a broad range of organic compounds in numerous types of samples [9].

An alternative solvent-minimized sample preparation approach to complement SPME appeared in the middle-to-late 1990s [10-12]; liquid-phase microextraction (LPME) utilizes only a small amount of solvent (low microliter range) for concentrating analytes from aqueous samples. It is simply a miniaturized format of liquid-liquid extraction (LLE) and overcomes many of its disadvantages as well as some of those of SPME (e.g. non-dependence on a commercial supplier and sample carryover). LPME is simple to implement and use, generally fast, and is characterized by its affordability and reliance on widely-available apparatus or materials [13]. The applications of LPME in environmental and biological analysis have been described in several papers [14-18].

LPME can be classified as two- $[12,19,20]$ and three-phase [21-24] categories. Two-phase microextraction is usually performed by suspending a drop (a few microli- 
ters) of organic solvent on the tip of either a Teflon rod or the needle tip of a microsyringe immersed in the stirred aqueous sample solution. Analytes are extracted into the organic solvent and then directly injected into a gas chromatograph (GC) or high-performance liquid chromatography (HPLC) for analysis. Hollow fiber (HF) two-phase microextraction has also been developed to enhance the extraction efficiency and to stabilize the extracted solvent microdrop. In three-phase microextraction, the ionizable analytes in the aqueous sample are extracted through a thin phase of organic solvent inside the pores of a polypropylene HF or an organic solvent layer held within a Teflon ring and then back extracted into another aqueous acceptor solution. Following this procedure the acceptor solution could be analyzed by HPLC or capillary electrophoresis (CE), without further treatment. It has been proven that HF-LPME is very useful for extraction of drugs and metabolites from biological matrices and pollutants from environmental samples with simultaneous clean-up of the matrices [25-28].

Tamoxifen (TAM) is an oral non-steroidal antiestrogen drug used in the treatment and prevention of breast cancer [29]. TAM's primary mechanism of action is competitive inhibition of the estrogen $\alpha$-receptor, thereby inhibiting growth of malignant breast cells. TAM administration for 5 years reduces the risk of recurrence of breast cancer both locally and systemically and improves overall survival rates. Moreover, with the significant grow in the use of TAM, the drug monitoring at trace level is of great importance.

Analytical techniques applied in the determination of TAM has been well documented, including TLC [30], GC [31,32], HPLC [33-35], CE [36-38], GC-MS [39], LC-MS [40,41] and CE-MS [42]. Additionally, some electrochemical methods such as voltammetry [43] have also been reported for TAM analysis. Nonetheless, the drug was determined in complex matrices by these techniques, usually after laborious manipulation of the sample before the instrumental analysis.

The aim of the present study is to assess the suitability of HF-LPME technique for the determination of TAM in biological fluids. The factors affecting the microextraction efficiency were studied in details and the optimal conditions were established. The resulting method was validated for quantitative purposes and then was applied to spiked real sample analysis in combination with high-performance liquid chromatography-ultraviolet detection (HPLC-UV).

\section{Experimental}

\subsection{Chemicals and Reagents}

All the reagents were of analytical grade. TAM citrate was kindly donated by Iran Hormone pharmaceutical company (Tehran, Iran). HPLC-grade methanol, acetonitrile, dihexylether, $n$-octanol, $n$-dodecane, $\mathrm{HCl}, \mathrm{NaCl}$, and $\mathrm{NaOH}$ were purchased from Merck (Darmstadt, Germany). Phosphate and ammonium acetate buffers were prepared from phosphoric and glacial acetic acid and their corresponding salts, respectively (Merck). The used reagent water was purified with a Milli-Q system from Millipore (Bedford, MA, USA).

\subsection{Preparation of Standard Solutions and Real Samples}

A proper amount of TAM citrate was dissolved in methanol to obtain stock solution with a concentration of $1000 \mathrm{mg} \cdot \mathrm{L}^{-1}$. Working standard solutions were freshly prepared by diluting the standard solutions of the analyte with the reagent water to the required concentrations. Both stock and working standard solutions were stored at $4^{\circ} \mathrm{C}$ in a refrigerator. The concentration of the drug in the preliminary experiments was $50 \mathrm{ng} \cdot \mathrm{mL}^{-1}$. Human urine sample was obtained from a healthy female and Iranian Blood Transfusion Organization (Tehran, Iran) was the supplier of the plasma sample as well. These samples were filtered through a $0.45 \mu \mathrm{m}$ pore-size cellulose acetate membrane filters prior to the extraction.

\subsection{Instrumentation}

The HPLC system consisted of a Shimadzu (Tokyo, Japan) LC-10 AV pump, a Rheodyne 7725 injector equipped with $20 \mu \mathrm{L}$ sample loop combined with a SPD-10 AV UV-Vis detector. Chromatographic separation was made on a Phenomenex CLC-C18 (150 mm $\times 4.6 \mathrm{~mm}$; $5 \mu \mathrm{m})$ column under isocratic elution condition. The mobile phase was a mixture of acetonitrile and ammonium acetate $(\mathrm{pH} 6.9 ; 0.05 \mathrm{M})(70 / 30, \mathrm{v} / \mathrm{v})$ with a flow rate of $1.0 \mathrm{~mL} \cdot \mathrm{min}^{-1}$. UV detection at $254 \mathrm{~nm}$ was used for quantification.

\subsection{Extraction Procedure}

All the HF-LPME experiments were performed using Accurel Q 3/2 polypropylene hollow fiber membrane (600 $\mu \mathrm{m}$ I.D., $200 \mu \mathrm{m}$ wall thickness, $0.2 \mu \mathrm{m}$ pore size) from Membrana (Wuppertal, Germany). The whole fiber was cut into small segments with the length of $9.0 \mathrm{~cm}$. One end of each resulting hollow fiber was heat-sealed using a soldering iron. A $25 \mu \mathrm{L}$ syringe model $702 \mathrm{NR}$ from Hamilton (Bonaduz, Switzerland) was employed to introduce the receiving phase (RP) solution into the lumen of the hollow fiber, to suspend the hollow fiber and also to inject the extracted analyte at the end of the ex- 
traction into the HPLC loop. Extraction and injection processes were performed in the following steps: 1) $15 \mathrm{~mL}$ of the aqueous sample solution (source phase; SP) was transferred into a $16 \mathrm{~mL}$ glass vial containing a $10 \mathrm{~mm} \times$ $4 \mathrm{~mm}$ magnetic stirring bar; 2) the vial was placed on a magnetic stirrer model ZMS 74 from ZAG Chimi Company (Tehran, Iran); 3) a carefully measured portion of $25 \mu \mathrm{L}$ of the receiving phase was injected into the hollow fiber; 4) the fiber was submerged in the organic solution (membrane phase; MP) for $5 \mathrm{~s}$ and then into the reagent water for $5 \mathrm{~s}$ for washing the extra organic solution from the surface of the fiber; 5) the fiber was bent into a U-shape and together with a small part of the supporting syringe needle was submerged in the sample solution; 6) the vial was covered with Para Film and stirred for a prescribed time period; 7) at the end of the extraction time, the hollow fiber was removed from the sample solution, and its closed end was cut and the receiving phase was withdrawn into the syringe; 8) finally $24 \mu \mathrm{L}$ of the receiving phase was injected into the HPLC. In initial experiments, the volumes of SP and RP solutions were $15 \mathrm{~mL}$ and $25 \mu \mathrm{L}$, respectively. Also, to obtain suitable signals in the optimization experiments, relatively high concentration of aqueous solution of TAM $\left(50 \mathrm{ng} \cdot \mathrm{mL}^{-1}\right)$ was used. All the experiments were done at room temperature and the SP was stirred at a rate of $1000 \mathrm{rpm}$ for $60 \mathrm{~min}$.

\subsection{Calculations}

The enrichment factor $(\mathrm{EF})$ and percent extraction of the drug were calculated by the following equations:

$$
\begin{gathered}
\mathrm{EF}=\mathrm{C}_{\mathrm{RP}} \text {, final } / \mathrm{C}_{\mathrm{SP}} \text {, initial } \\
\text { Extraction }(\%)=\mathrm{EF} \times \mathrm{V}_{\mathrm{RP}} / \mathrm{V}_{\mathrm{SP}} \times 100
\end{gathered}
$$

where $C_{R P \text {, final }}$ and $C_{S P}$, initial are the final and initial concentrations of the drug in $\mathrm{RP}$ and $\mathrm{SP}$, respectively. $\mathrm{C}$ RP,final of the extracted drug was calculated from the calibration curve. $\mathrm{V}_{\mathrm{SP}}$ and $\mathrm{V}_{\mathrm{RP}}$ are the volumes of $\mathrm{SP}$ and $\mathrm{RP}$, respectively.

\section{Results and Discussion}

\subsection{Basic Principle of the Extraction}

In three-phase LPME, the analyte is extracted from the aqueous sample solution (SP) into the organic phase immobilized within the pores of the hollow fiber known as membrane phase (MP) and then it is back-extracted into RP located inside the hollow fiber. For an analyte such as A, the extraction process can be written as:

$$
\mathrm{A}_{\mathrm{SP}} \leftrightarrow \mathrm{A}_{\mathrm{MP}} \leftrightarrow \mathrm{A}_{\mathrm{RP}}
$$

The initial amount of analyte, $n_{i}$, is equal to the sum of individual amounts of analyte present in all the phases during the whole extraction process:

$$
\mathrm{n}_{\mathrm{i}}=\mathrm{n}_{\mathrm{SP}}+\mathrm{n}_{\mathrm{MP}}+\mathrm{n}_{\mathrm{RP}}
$$

where $n_{\mathrm{SP}}$ is the amount of analyte in the SP solution, $n$ MP the amount of analyte in the MP solution and $n_{R P}$ is the amount of analyte in the RP solution. At the equilibrium condition, Equation (3) can be written as:

$$
\mathrm{C}_{\mathrm{i}} \mathrm{V}_{\mathrm{SP}}=\mathrm{C}_{\text {eq.SP }} \mathrm{V}_{\mathrm{SP}}+\mathrm{C}_{\text {eq.MP }} \mathrm{V}_{\mathrm{MP}}+\mathrm{C}_{\text {eq.RP }} \mathrm{V}_{\mathrm{RP}}
$$

where $C_{i}$ is the initial concentration of analyte, $C_{\text {eq.SP }}, C$ eq.MP and $\mathrm{C}_{\text {eq.RP }}$ are analyte concentrations in the SP, MP and RP solutions at equilibrium condition, respectively. $\mathrm{V}_{\mathrm{SP}}, \mathrm{V}_{\mathrm{MP}}$ and $\mathrm{V}_{\mathrm{RP}}$ are the volumes of the source, membrane and receiving phases, respectively. It is worth noting that in all cases, the analytical signal was recorded as the function of extraction percent (\%) versus each parameter regarding the optimization process.

\subsection{Organic Solvent Selection}

Selection of the solvent should be based on comparison of selectivity, extraction efficiency and the level of toxicity. In addition, the polarity of the organic phase should be similar to that of the polypropylene fiber so that it can be easily immobilized within the pores of the fiber. This function greatly affects the performance of HF-LPME, since extraction occurs on the surface of the immobilized solvent. Three different organic solvents (i.e. dihexylether, $n$-octanol and $n$-dodecane) were used in the present work as organic membrane solvents. Based on the results, the best solvent proved to be dihexylether. Thus, dihexylether was chosen as the membrane solvent in the subsequent studies.

\subsection{Effect of Compositions of SP and RP Solutions}

The effect of the concentration of $\mathrm{NaOH}$ in the SP solution on $\mathrm{EF}$ at the range of $0.0-0.1 \mathrm{M}$ was studied. As can be seen in Figure 1, the EF had its maximum value in the presence of $0.01 \mathrm{M} \mathrm{NaOH}$ (pH 11.8). In subsequent experiments, the $\mathrm{pH}$ of SP solution was adjusted at 11.8 using $4 \mathrm{M}$ of $\mathrm{NaOH}$ solution. At this $\mathrm{pH}$, TAM is mostly in its free form. The dependence of the EF of TAM on $\mathrm{HCl}$ concentration in the RP solution at the concentration range of $0.0-0.1 \mathrm{M}$ was also investigated. Based on Figure 1, it proved that $\mathrm{EF}$ had its maximum value in the presence of $0.01 \mathrm{M} \mathrm{HCl}(\mathrm{pH} 2)$. It is noteworthy that degradation of $\mathrm{C} 18$ column can be accelerated in the presence of $\mathrm{Cl}^{-}$ions, thus in further experiments, the $\mathrm{pH}$ of the RP solution was adjusted at 2 using phosphate buffer. At this $\mathrm{pH}$, TAM is mostly ionized. Thus, in the present study, gradient of the $\mathrm{pH}$ between the SP 


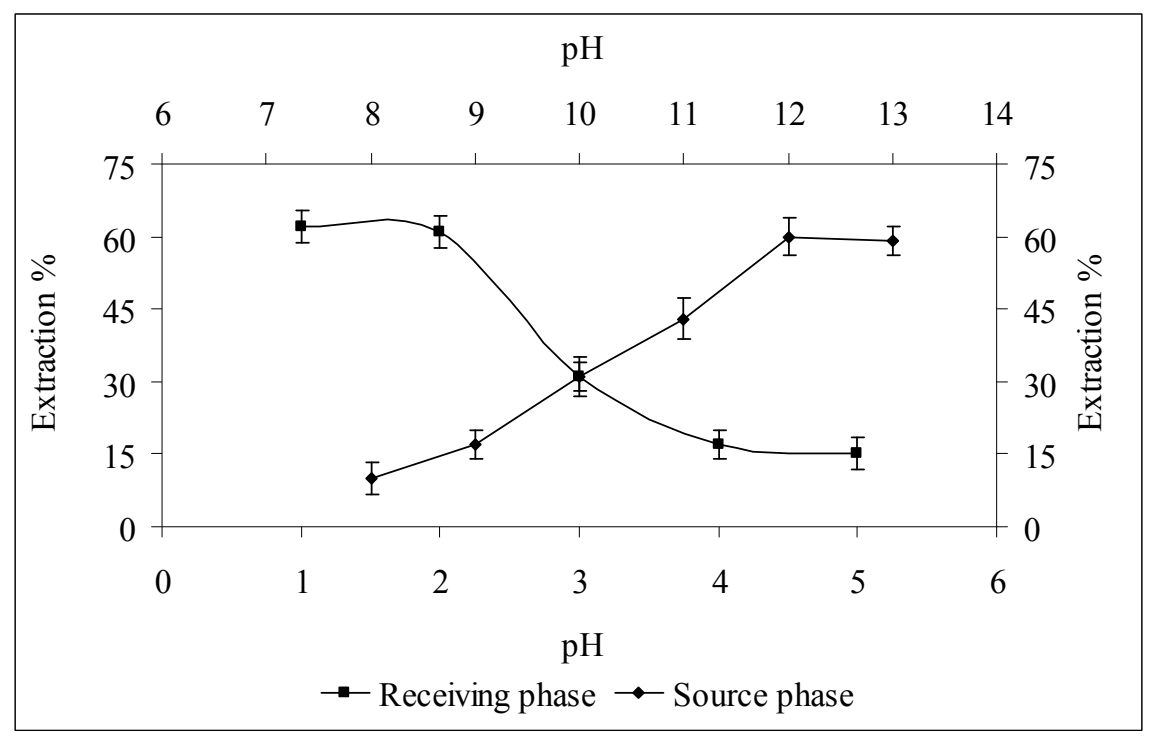

Figure 1. The effect of $\mathrm{pH}$ of source and receiving phase on the extraction efficiency. Extraction conditions: $\mathrm{C}$ TAM, $50 \mathrm{ng} \cdot \mathrm{mL}^{-1}$; SP, $15 \mathrm{~mL}$; RP, $25 \mu \mathrm{L}$; stirring rate, $1000 \mathrm{rpm}$; extraction time, $60 \mathrm{~min}$.

and the RP solutions is a driving force for the drug transport which was in accordance with the already expectations.

\subsection{Agitation Speed}

Like other microextraction techniques, the extraction in HF-LPME can be enhanced by agitation of the sample solution. Thereby, reducing the "time" required to attain thermodynamic equilibrium especially for the higher molecular mass analytes [20]. In HF-LPME, the organic solvent is sealed and protected by the hydrophobic hollow fiber membrane, so it is easier to handle and it can tolerate higher stirring speeds. In our experiments, partitioning of the analytes into the organic solvent was enhanced by increasing the stirring speed from 250 to 1000 rpm (Figure 2). Thus, the stirring speed with the maximum value $(1000 \mathrm{rpm})$ was chosen for the rest of the experiments.

\subsection{Salt Effect}

The effect of salt addition on EF was examined by adding sodium chloride to aqueous samples at the concentration levels of $0 \%-3 \% \mathrm{w} / \mathrm{v}$ (Figure 2). The EF of TAM was decreased by increasing of the salt concentration. This effect may be due to increased interactions between the analyte and salt in solution with increasing salt concentration. Such interactions would tend to restrict movement of the analyte from the SP to the membrane solvent. So, all the subsequent experiments were performed in the absence of salt. It is worth noting that in the biological samples due to existence of salts, lower extractions in comparison with the aqueous sample may be expected.

\subsection{Extraction Time}

LPME is not an exhaustive extraction technique, thus maximum sensitivity is attained at equilibrium condition. On the other hand, complete equilibrium need not be attained for accurate and precise analysis. However, choosing an exact extraction time is essential to obtain good precision [44]. Therefore, extraction time is one of the most important factors influencing the extraction efficiency. In this study, EF of the drug was investigated as a function of time in the range of $15-75 \mathrm{~min}$. Then, EF of the drug was increased by increasing of the extraction time. As shown in Figure 3, the optimal extraction time was $60 \mathrm{~min}$. Thus, $60 \mathrm{~min}$ was chosen as the extraction time in the subsequent experiments. It is noteworthy that the optimum extraction time is dependent on sample composition and may be re-evaluated for real samples to obtain suitable EFs.

\subsection{Evaluation of the Method Performance}

The calibration curves of TAM were plotted in three different sample solutions. For each level, three replicate extractions were performed under the optimal conditions. Dynamic linear ranges (DLRs) and limits of detection (LODs), defined as the analytical signal which is larger than the blank by multiple three of the variation in the blank, all were calculated and tabulated in Table 1. Furthermore, based on Equation (1) the highest attainable EF was found to be 360 in aqueous medium (at the 


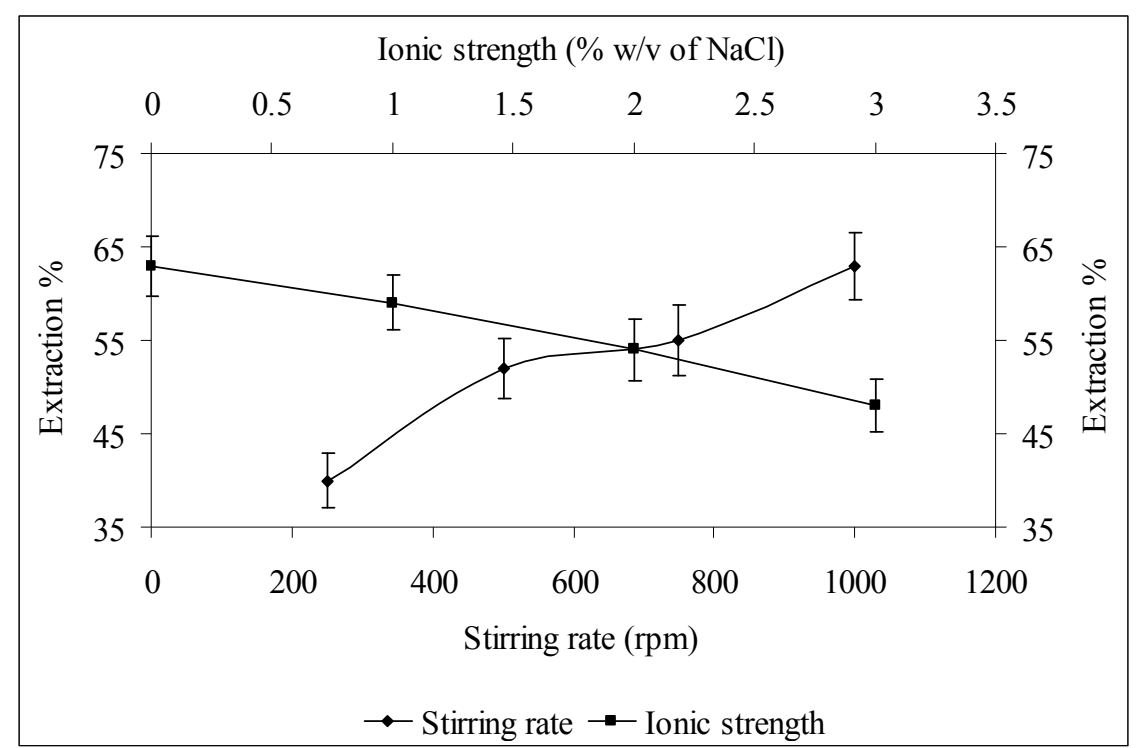

Figure 2. The effects of salt addition and stirring rate on the extraction efficiency. Extraction conditions: $\mathrm{C}_{\mathrm{TAM}}, 50 \mathrm{ng} \cdot \mathrm{mL}^{-1}$; SP, $15 \mathrm{~mL}$ of $0.01 \mathrm{M} \mathrm{NaOH}$ (pH 11.8); RP, $25 \mu \mathrm{L}$ of $0.01 \mathrm{M}$ phosphate buffer (pH 2.0); extraction time, $60 \mathrm{~min}$.

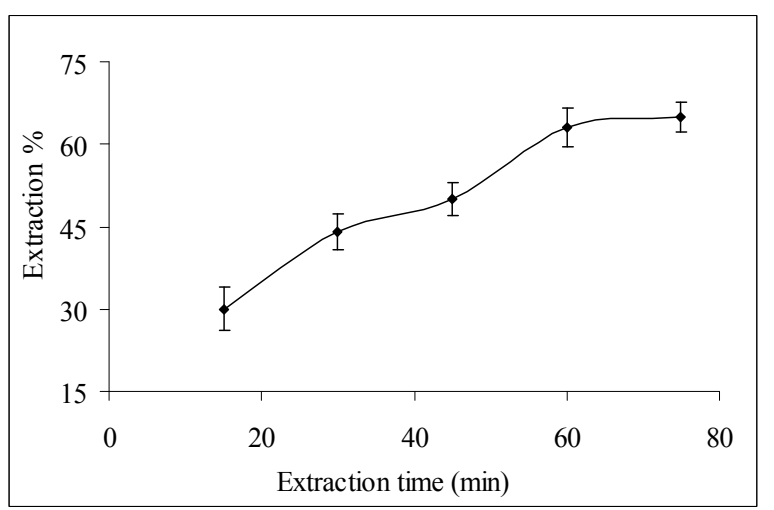

Figure 3. The effect of time on the extraction efficiency. Extraction conditions: $C$ TAM, $50 \mathrm{ng} \cdot \mathrm{mL}^{-1}$; SP, $15 \mathrm{~mL}$ of 0.01 M NaOH (pH 11.8); RP, $25 \mu \mathrm{L}$ of $0.01 \mathrm{M}$ phosphate buffer (pH 2.0); stirring rate, $1000 \mathrm{rpm}$.

Table 1. The quantitative data obtained after HF-LPME and HPLC-UV determination of TAM.

\begin{tabular}{lcc}
\hline Sample & LOD $\left(\mathrm{ng} \cdot \mathrm{mL}^{-1}\right)$ & DLR $\left(\mathrm{ng} \cdot \mathrm{mL}^{-1}\right)$ \\
\hline Aqueous & 0.5 & $1-500$ \\
Human urine & 2.5 & $10-250$ \\
Human plasma & 5.0 & $15-200$ \\
\hline
\end{tabular}

concentration level of $\left.50 \mathrm{ng} \cdot \mathrm{mL}^{-1}\right)$.

\subsection{Analysis of Spiked Real Samples}

It is apparent that porous hollow fiber functions as a filter in dirty samples, since particles and also large molecules, which can also be soluble in the organic solvent, will not be extracted. In this way, the present developed microextraction technique can be potentially used to extract drugs from complex matrices, while preventing co-extraction of other extractable components. In order to assess the applicability of the extraction method to the analysis of the drug in spiked real samples with complex matrices, the spiked urine and plasma samples were extracted and analyzed using the proposed method under the optimum conditions which as follows:

\subsubsection{Human Urine}

The human urine sample was diluted two times by double distilled water. Under the optimum conditions, the percent relative intra-day and inter-day standard deviations (RSD\%) based on three replicate determinations were 3.7 and 7.5, respectively. The percent relative recovery of the drug in spiked human urine sample at spiking level of $20.0 \mathrm{ng} \cdot \mathrm{mL}^{-1}$ was 89 (Table 2).

\subsubsection{Human Plasma}

TAM is extensively bounded to plasma proteins $(99 \%)$

Table 2. Results obtained for the analysis of TAM in two spiked biological samples.

\begin{tabular}{llc}
\hline Sample & & \\
\hline Urine & Concentration $\left(\mathrm{ng} \cdot \mathrm{mL}^{-1}\right)$ & $\mathrm{ND}^{\mathrm{a}}$ \\
$\left(20.0 \mathrm{ng} \cdot \mathrm{mL}^{-1}\right.$ & Found $\left(\mathrm{ng} \cdot \mathrm{mL}^{-1}\right)$ & 17.8 \\
added) & Relative recovery $(\%)$ & 89 \\
& Intra-day RSD\% $(n=3)$ & 3.7 \\
& Inter-day RSD\% & 7.5 \\
& Concentration $\left(\mathrm{ng} \cdot \mathrm{mL}^{-1}\right)$ & $\mathrm{ND}$ \\
Plasma & Found $\left(\mathrm{ng} \cdot \mathrm{mL}^{-1}\right)$ & 22.5 \\
$\left(25.0 \mu \mathrm{g} \cdot \mathrm{L}^{-1}\right.$ added) & Relative recovery $(\%)$ & 90 \\
& Intra-day RSD $\%(n=3)$ & 4.2 \\
& Inter-day RSD $\%$ & 7.8 \\
\hline
\end{tabular}

${ }^{a}$ Not Detected. ${ }^{b}$ For three consecutive days. 
[45], and should be librated prior to the extraction. Plasma sample $(5 \mathrm{~mL})$ was spiked with particular level of the drug and vortexed for $3 \mathrm{~min}$. The mixture was added with $5 \mathrm{~mL}$ of acetonitril to disturb the drug protein binding. The process eventually led to the precipitation of proteins. Subsequently, the sample was centrifuged at $4000 \mathrm{rpm}$ for $5 \mathrm{~min}$. The whole resulting supernatant phase was then transferred into a sample vial, followed by simultaneous dilution (up to $15 \mathrm{~mL}$ ) and adjustment of $\mathrm{pH}$ at the optimal value $(\mathrm{pH}=11.8)$. Under the optimum conditions, the percent relative intra-day and inter-day standard deviations (RSD \%) based on three replicate determinations were 4.2 and 7.8 , respectively. The percent relative recovery of the drug in human plasma sample at spiking level of $25.0 \mathrm{ng} \cdot \mathrm{mL}^{-1}$ was 90 , (Table
2). Figure 4 depicts the chromatograms of the spiked (at the concentration level of $25.0 \mathrm{ng} \cdot \mathrm{mL}^{-1}$ ) and non-spiked plasma samples with TAM under the optimum conditions. The obtained chromatograms revealed that in spite of complexity of the sample matrix, due to the high sample clean-up performance, almost no other components than the target analyte were recovered in the RP solution.

\section{Conclusions}

The results from this work showed that the HF-LPME technique in combination with HPLC-UV is a valid means of enrichment and quantification of TAM at trace level in spiked human urine and plasma samples. The established procedure demonstrated good sample clean-

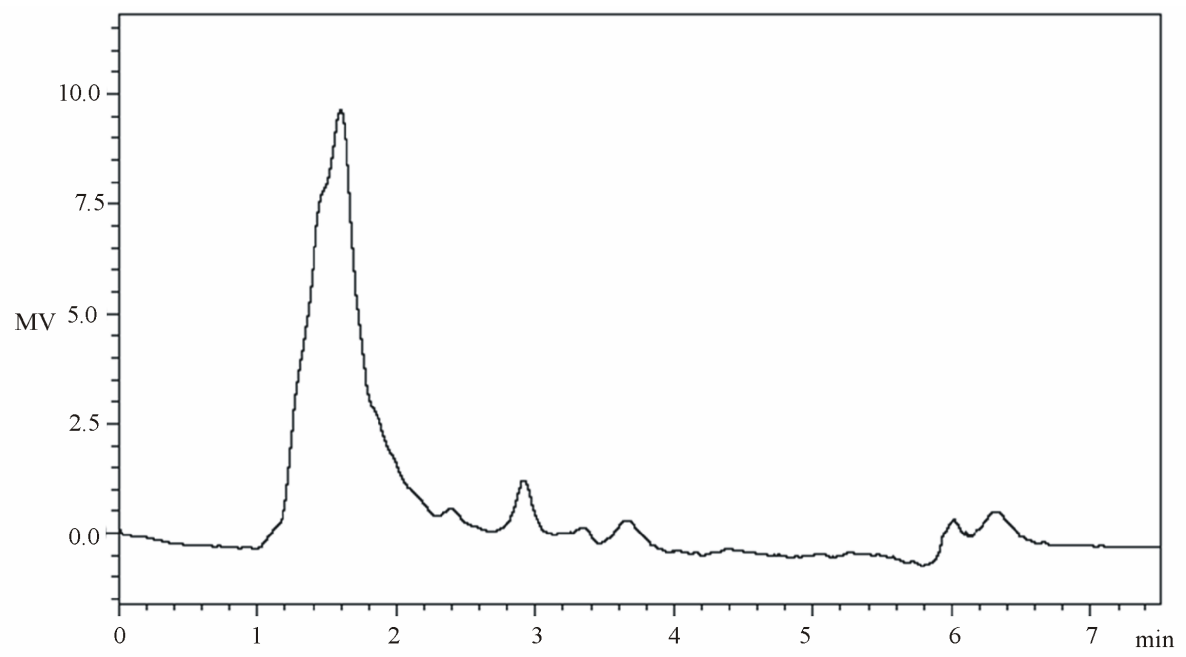

(a)

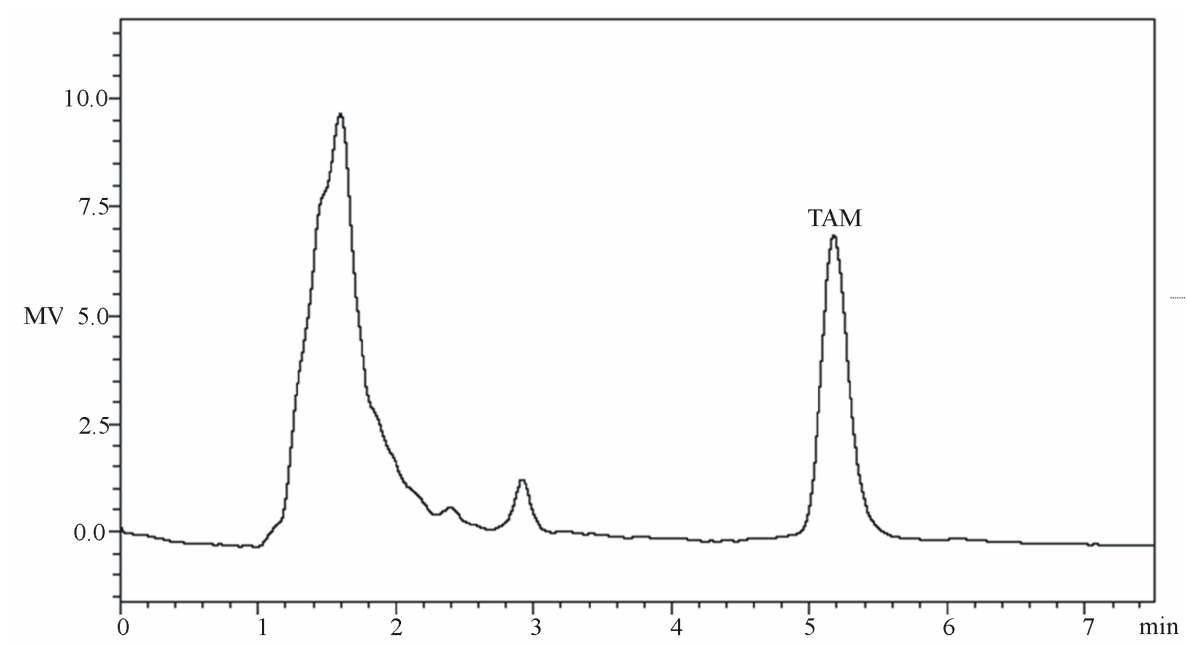

(b)

Figure 4. The chromatograms of (a) non-spiked plasma samples with TAM under the optimum conditions, and (b) the spiked (at the concentration level of $25.0 \mathrm{ng} \cdot \mathrm{mL}^{-1}$ ). 
-up with high sensitivity and reproducibility. Despite the complexity of the sample matrix, due to the high sample clean-up performance, almost no other components except for the target was recovered in the receiving phase solution. Moreover, excellent extraction recoveries were achieved demonstrating the fact that the whole determination is almost independent of the matrix.

\section{References}

[1] S. C. Moldoveanu and V. David, "Sample Preparation in Chromatography," Elsevier, Amsterdam, 2002.

[2] J. Pawliszyn, "Sampling and Sample Preparation for Field and Laboratory," Elsevier, Amsterdam, 2002.

[3] J. Pawliszyn, "Sample Preparation: Quo Vadis?" Analytical Chemistry, Vol. 75, No. 11, 2003, pp. 2543-2558. doi:10.1021/ac034094h

[4] R. M. Smith, "Before the Injection-Modern Methods of Sample Preparation for Separation Techniques," Journal of Chromatography A, Vol. 1000, No. 1-2, 2003, pp. 3-27. doi:10.1016/S0021-9673(03)00511-9

[5] D. E. Raynie, "Modern Extraction Techniques," Analytical Chemistry, Vol. 76, No. 16, 2004, pp. 4659-4664. doi:10.1021/ac040117w

[6] D. E. Raynie, "Modern Extraction Techniques," Analytical Chemistry, Vol. 78, No. 12, 2006, pp. 3997-4004. doi:10.1021/ac060641y

[7] C. L. Arthur and J. Pawliszyn, "Solid Phase Microextraction with Thermal Desorption Using Fused Silica Optical Fibers," Analytical Chemistry, Vol. 62, No. 19, 1990, pp. 2145-2148. doi:10.1021/ac00218a019

[8] J. Pawliszyn, "Solid Phase Microextraction: Theory and Practice," Wiley-VCH Inc., New York, 1997.

[9] J. Pawliszyn, "Applications of Solid Phase Microextraction," Royal Society of Chemistry, London, 1999.

[10] H. Liu and P. K. Dasgupta, "Analytical Chemistry in a Drop. Solvent Extraction in a Microdrop," Analytical Chemistry, Vol. 68, No. 11, 1996, pp.1817-1821. doi:10.1021/ac960145h

[11] F. F. Cantwell and M. A. Jeannot, "Solvent Microextraction into a Single Drop," Analytical Chemistry, Vol. 68, No. 13, 1996, pp. 2236-2240.

[12] Y. Wang, Y. C. Kwok, Y. He and H. K. Lee, "Application of Dynamic Liquid-Phase Microextraction to the Analysis of Chlorobenzenes in Water by Using a Conventional Microsyringe," Analytical Chemistry, Vol. 70, No. 21, 1998, pp. 4610-4614. doi:10.1021/ac9804339

[13] L. Xu, C. Basheer and H. K. Lee, "Developments in Single-Drop Microextraction," Journal of Chromatography A, Vol. 1152, No. 1-2, 2007, pp. 184-192. doi:10.1016/j.chroma.2006.10.073

[14] L. Meng, X. Liu, B. Wang, G. Shen, Z. Wang and M. Guo, "Simultaneous Derivatization and Extraction of Free Cyanide in Biological Samples with Home-Made Hollow Fiber-Protected Headspace Liquid-Phase Microextraction Followed by Capillary Electrophoresis with
UV Detection," Journal of Chromatography B, Vol. 877, No. 29, 2009, pp. 3645-3651. doi:10.1016/j.jchromb.2009.09.006

[15] Y. Li, Y. Xiong, J. Fang, L. Wang and Q. Liang, “Application of Hollow Fiber Liquid-Phase Microextraction in Identification of Oil Spill Sources," Journal of Chromatography A, Vol. 1216, No. 34, 2009, pp. 6155-6161. doi:10.1016/j.chroma.2009.06.069

[16] N. Sharma, A. K. K. V. Pillai, N. Pathak, A. Jain and K. K. Verma, "Liquid-Phase Microextraction and Fibre-Optics-Based Cuvetteless CCD-Array Micro-Spectrophotometry for Trace Analysis," Analytica Chimica Acta, Vol. 648, No. 2, 2009, pp. 183-193. doi:10.1016/j.aca.2009.07.006

[17] Q. Zhou, H. Bai, G. Xie and J. Xiao, "Trace Determination of Organophosphorus Pesticides in Environmental Samples by Temperature-Controlled Ionic Liquid Dispersive Liquid-Phase Microextraction," Journal of Chromatography A, Vol. 1188, No. 2, 2008, pp. 148-153. doi:10.1016/j.chroma.2008.02.094

[18] H. Bagheri, F. Khalilian, E. Babanezhad, A. Eshaghi and M.-R. Rouini, "Modified Solvent Microextraction with Back Extraction Combined with Liquid Chromatography-Fluorescence Detection for the Determination of Citalopram in Human Plasma," Analytica Chimica Acta, Vol. 610, No. 2, 2008, pp. 211-216. doi:10.1016/j.aca.2008.01.047

[19] A. L. Theis, J. W. Waldack, S. M. Hansen and M. A. Jeannot, "Headspace Solvent Microextraction," Analytical Chemistry, Vol. 73, No. 23, 2001, pp. 5651-5654. doi: $10.1021 / \mathrm{ac} 015569 \mathrm{c}$

[20] L. Zhao and H. K. Lee, "Liquid-Phase Microextraction Combined with Hollow Fiber as a Sample Preparation Technique Prior to Gas Chromatography/Mass Spectrometry," Analytical Chemistry, Vol. 74, No. 11, 2002, 2486-2492. doi:10.1021/ac011124c

[21] M. H. Ma and F. F. Cantwell, "Solvent Microextraction with Simultaneous Back-Extraction for Sample Cleanup and Preconcentration: Quantitative Extraction," Analytical Chemistry, Vol. 70, No. 18, 1998, pp. 3912-3919. doi:10.1021/ac980174n

[22] M. H. Ma and F. F. Cantwell, "Solvent Microextraction with Simultaneous Back-Extraction for Sample Cleanup and Preconcentration into a Single Microdrop," Analytical Chemistry, Vol. 71, No. 2, 1999, pp. 388-393. doi:10.1021/ac9805899

[23] S. Pedersen-Bjergaard and K. E. Rasmussen, "LiquidLiquid-Liquid Microextraction for Sample Preparation of Biological Fluids Prior to Capillary Electrophoresis," Analytical Chemistry, Vol. 71, No. 14, 1999, pp. 26502656. doi:10.1021/ac990055n

[24] T. G. Halvorsen, S. Pedersen-Bjergaard and K. E. Rasmussen, "Reduction of Extraction Times in Liquid-Phase Microextraction," Journal of Chromatography B, Vol. 71, No. 2, 2001, pp. 219-226.

[25] K. E. Rasmussen and S. Pedersen-Bjergaard, "Developments in Hollow Fibre Based Liquid-Phase Microextraction," Trends in Analytical Chemistry, Vol. 23, No. 1, 
2004, pp. 1-10. doi:10.1016/S0165-9936(04)00105-0

[26] H. G. Ugland, M. Krogh and K. E. Rasmussen, "LiquidPhase Microextraction as a Sample Preparation Technique Prior to Capillary Gas Chromatographic-Determination Ofbenzodiazepines in Biological Matrices," Journal of Chromatography B, Vol. 749, No. 1, 2000, pp. 85-92. doi:10.1016/S0378-4347(00)00382-0

[27] K. E. Rasmussen, S. Pedersen-Bjergaard, M. Krogh, H. Ugland and T. Grønhaug, "Development of a Simple in-Vial Liquid-Phase Microextraction Device for Drug Analysis Compatible with Capillary Gas Chromatography, Capillary Electrophoresis and High-Performance Liquid Chromatography," Journal of Chromatography A, Vol. 873, No. 1, 2000, pp. 3-11. doi:10.1016/S0021-9673(99)01163-2

[28] T. G. Halvorsen, S. Pedersen-Bjergaard and K. E. Rasmussen, "Liquid-Phase Microextraction and Capillary Electrophoresis of Citalopram, an Antidepressant Drug," Journal of Chromatography A, Vol. 909, No. 1, 2001, pp. 87-93. doi:10.1016/S0021-9673(00)00868-2

[29] E. Robinson, G. G. Kimmick and H. B. Muss, "Tamoxifen in Postmenopausal Women: A Safety Perspective," Drugs \& Aging, Vol. 8, No. 5, 1996, pp. 329-337. doi:10.2165/00002512-199608050-00002

[30] J. V. Kemp, H. K. Adam, A. E. Wakeling and R. Slater, "Identification and Biological Activity of Tamoxifen Metabolites in Human Serum," Biochemical Pharmacology, Vol. 32, No. 13, 1983, pp. 2045-2052. doi:10.1016/0006-2952(83)90425-2

[31] R. Mihailescu, H. Y. Aboul-Enein and M. D. Efstatide, "Identification of Tamoxifen and Metabolites in Human Male Urine by GC/MS," Biomedical Chromatography, Vol. 14, No. 3, 2000, pp.180-183.

doi:10.1002/1099-0801(200005)14:3<180::AID-BMC95 8>3.0.CO;2-T

[32] R. T. Sane, S. V. Desai, K. K. Sonawne and V. G. Nayak, "Quantitative Gas Chromatographic Determination of Tamoxifen Citrate in Pharmaceuticals," Journal of Chromatography A, Vol. 331, No. 2, 1985, pp. 432-436. doi:10.1016/0021-9673(85)80052-2

[33] R. R. Brown, R. Bain and V. C. Jordan, "Determination of Tamoxifen and Metabolites in Human Serum by High-Performance Liquid Chromatography with Post-Column Fluorescence Activation," Journal of Chromatography B, Vol. 272, 1983, pp. 351-358. doi:10.1016/S0378-4347(00)86138-1

[34] J. E. Manns, S. Hanks and J. E. Brown, "Optimised Separation of E- and Z-Isomers of Tamoxifen, and Its Principal Metabolites Using Reversed-Phase High Performance Liquid Chromatography," Journal of Pharmaceutical and Biomedical Analysis, Vol. 16 , No. 5, 1998, pp. 847-852. doi:10.1016/S0731-7085(97)00116-7

[35] Y.-B. Zhu, Q. Zhang, J.-J. Zou, C.-X. Yu and D.-W. Xiao, "Optimizing High-Performance Liquid Chromatography Method with Fluorescence Detection for Quantification of Tamoxifen and Two Metabolites in Human Plasma: Application to a Clinical Study," Journal of Pharmaceutical and Biomedical Analysis, Vol. 46, No. 2, 2008, pp. 349-355. doi:10.1016/j.jpba.2007.10.012
[36] J. M. Sanders, L. T. Burka, M. D. Shelby, R. R. Newbold and M. L. Cunningham, "Determination of Tamoxifen and Metabolites in Serum by Capillary Electrophoresis Using a Nonaqueous Buffer System," Journal of Chromatography B, Vol. 695, No. 1, 1997, pp. 181-185. doi:10.1016/S0378-4347(97)00099-6

[37] X. F. Li, S. J. Carter and N. J. Dovichi, "Non-Aqueous Capillary Electrophoresis of Tamoxifen and Its Acid Hydrolysis Products," Journal of Chromatography A, Vol. 895, No. 1-2, 2000, pp. 81-85. doi:10.1016/S0021-9673(00)00661-0

[38] J. Rodríguez Flores, J. J. Berzas Nevado, A. M. Contento Salcedo and M. P. Cabello Díaz, "Nonaqueous Capillary Electrophoresis Method for the Analysis of Tamoxifen, Imipramine and Their Main Metabolites in Urine," Talanta, Vol. 65, No. 1, 2005, pp. 155-162.

[39] C. Murphy, T. Fotsis, P. Pantzar, H. Adlercreutz and F. Martin, "Analysis of Tamoxifen, N-Desmethyltamoxifen and 4-Hydroxytamoxifen Levels in Cytosol and $\mathrm{KCl}-$ -Nuclear Extracts of Breast Tumours from Tamoxifen Treated Patients by Gas Chromatoraphy-Mass Spectrometry (GC-MS) Using Selected Ion Monitoring (SIM)," Journal of Steroid Biochemistry, Vol. 28, No. 6, 1987, pp. 609-618. doi:10.1016/0022-4731(87)90387-6

[40] H. K. Lim, S. Stellingweif, S. Sisenwine and K. W. Chan, "Rapid Drug Metabolite Profiling Using Fast Liquid Chromatography, Automated Multiple-Stage Mass Spectrometry and Receptor-Binding," Journal of Chromatography A, Vol. 83, No. 2, 1999, pp. 227-241. doi:10.1016/S0021-9673(98)00956-X

[41] Z. L. Zhang and J. L. Zhou, "Simultaneous Determination of Various Pharmaceutical Compounds in Water by Solid-Phase Extraction-Liquid Chromatography-Tandem Mass Spectrometry," Journal of Chromatography A, Vol. 1154, No. 1-2, 2007, pp. 205-213. doi:10.1016/i.chroma.2007.03.105

[42] W. Lu, G. K. Poon, P. L. Carmichael and R. B. Cole, "Analysis of Tamoxifen and Its Metabolites by on-Line Capillary Electrophoresis-Electrospray Ionization Mass Spectrometry Employing Nonaqueous Media Containing Surfactants," Analytical Chemistry, Vol. 68, No. 4, 1996, pp. 668-674. doi:10.1021/ac950786x

[43] P. Daneshgar, P. Norouzi, M. R. Ganjali and H. A. Zamani, "Ultrasensitive Flow-Injection Electrochemical Method for Detection of Anticancer Drug Tamoxifen," Talanta, Vol. 77, No. 3, 2009, pp. 1075-1080. doi:10.1016/i.talanta.2008.08.027

[44] S. Palmarsdottir, E. Thordarson, L. E. Edholm, J. A. Jonsson and L. Mathiasson, "Miniaturized Supported Liquid Membrane Device for Selective on-Line Enrichment of Basic Drugs in Plasma Combined with Capillary Zone Electrophoresis," Analytical Chemistry, Vol. 69, No. 9, 1997, pp. 1732-1737.

[45] S. C. Paterson, C. K. Lim and K. D. Smith, "Analysis of the Interaction between Alpha-1-Acid Glycoprotein and Tamoxifen and Its Metabolites," Biomedical Chromatography, Vol. 17, No. 2-3, 2003, pp. 143-148. doi: $10.1002 / \mathrm{bmc} .230$ 